\title{
Reinnervation of the Extraocular Muscles in Goldfish is Nonselective
}

\author{
Steven S. Scherer ${ }^{1}$ \\ Division of Biological Sciences, The University of Michigan, Ann Arbor, Michigan 48109
}

The selectivity of axonal regeneration to the extraocular muscles in teleosts has been reinvestigated by mapping, with retrogradely transported HRP, the motor pools of the muscles innervated by the oculomotor nerve. In normal goldfish, the motoneurons of the superior rectus, inferior rectus, and inferior oblique muscles formed discrete, nonoverlapping motor pools; the motor pool of the medial rectus muscle overlapped with those of the inferior oblique and inferior rectus muscles. In fish whose oculomotor nerve had regenerated (after intracranial transection), in contrast, many motoneurons in other, inappropriate motor pools reinnervated the superior rectus and inferior oblique muscles (the only muscles examined in lesioned animals). Furthermore, these inappropriate motoneurons continued to project to these muscles for at least 1 year.

The oculomotor nerve and its molecular branches were examined by light and electron microscopy to determine the pathway by which axons regenerated to their muscles. Axons regenerated within the basal laminae of Schwann cells, which persisted in the distal nerve-stump after a lesion. After labeling the inferior oblique nerve with HRP in regenerated nerves, there were labeled axons in all of the muscular branches; this indicates that regenerating axons branched, which was confirmed by finding an increased number of myelinated axons in other, regenerated inferior oblique nerves. Thus, different branches of the same axons sometimes reinnervated different muscles.

These results demonstrate that regenerating axons in the oculomotor nerve are misdirected to inappropriate muscles, and do not selectively reinnervate individual muscles, as had been previously suggested (Sperry and Arora, 1965).

After axotomy, certain axons in both the central and the peripheral nervous system of vertebrates can regenerate and preferentially reconnect with their original targets. This selective reinnervation restores normal function in, for example, the retinotectal system of anamniotic vertebrates and the autonomic ganglia of mammals (reviewed in Purves and Lichtman, 1984). Whether skeletal muscles are selectively reinnervated by regenerating motor axons depends on the particular taxonomic group. In mammals and anuran amphibians, reinnervation following transection of peripheral nerves is nonselective, whereas the converse is thought to be true in urodele amphibians and teleost fish.

Received Feb. 19, 1985; revised June 10, 1985; accepted July 16, 1985.

I thank Drs. J. R. Fetcho, R. I. Hume, and P. A. Raymond for useful discussion; Ms. D. E. Scherer for drafting the figures; and especially Dr. S. S. Easter, Jr. for his guidance in all phases of this work. I was supported by a training grant from the National Eye Institute (EY-07022) and the Medical Scientist Training Program. This work was supported by a research grant from the National Eye Institute, EY00168 (to S. S. Easter, Jr.) and was submitted in partial fulfillment of the requirements for a Ph.D. from The University of Michigan.

Correspondence should be addressed to Steven S. Scherer, M.D., Ph.D., Department of Neurology, The Hospital of the University of Pennsylvania, 3400 Spruce Street, Philadelphia, PA 19104.

'Present address: Department of Neurology, The Hospital of the University of Pennsylvania, 3400 Spruce Street, Philadelphia, PA 19104.

Copyright (c) 1986 Society for Neuroscience $0270-6474 / 86 / 030764-10 \$ 02.00 / 0$
Since the classic work of Ramón y Cajal (1928), axonal regeneration in the peripheral nerves of mammals has been believed to be nonselective. After transection, the Schwann cells and their collagenous sheaths (the so-called Schwann, endoneurial, or neurilemmal tubes; see Thomas, 1964) persist in the distal nerve-stump, but the continuity of these collagenous tubes between the proximal and distal nerve-stumps is disrupted. $\mathrm{Re}-$ generating axons from the proximal nerve-stump reenter these Schwann tubes, apparently at random, and once inside a particular Schwann tube, a regenerating axon follows it distally to its target. Since regenerating axons branch near the site of transection, different branches of the same axon may reinnervate different targets.

The aberrant pattern of reinnervation that results from this axonal misdirection has been well documented in mammals. First, after regeneration of transected nerves, axon reflexes betwecn ncrve-branches distal to the transection can be elicited, showing that individual axons have branches in more than one nerve-branch (Osborne and Kilvington, 1908a, b). [When one branch of a nerve is stimulated electrically, and an action potential is recorded in another, this is an "axon reflex." This is thought to indicate axonal branching near the lesion, proximal to the branching of the nerve itself, so that electrical impulses are transmitted retrogradely to the axonal branch point(s), then orthogradely to the other axonal branch(es).] Second, electrophysiological studies have shown the disruption of the normal organization of both motor and sensory axons in regenerated nerves (Horch, 1979; Langley, 1897; Weiss and Hoag, 1946). Third, more recent anatomical techniques have demonstrated inappropriately projecting motoneurons by labeling them with retrogradely transported HRP in both mammals and anuran amphibians (Brushart and Mesulam, 1980; Mizuno et al., 1980; Westerfield and Powell, 1983). Finally, since the reviews of Ford and Woodhall (1938) and Sperry (1945), it has been widely accepted that in mammals, at least some of these misdirected axons form functional connections that result in permanently abnormal behavior, and this finding has subsequently been confirmed in anurans (Sperry, 1947; Westerfield and Powell, 1983).

In contrast, axonal regeneration in teleost fish and urodele amphibians is believed to be exceptional because normal movements are restored after nerve-transection (Mark, 1965; Sperry and Arora, 1965; Weiss, 1936). Electrophysiological studies in urodeles have suggested two possible mechanisms: individual motor axons may regenerate preferentially to their appropriate muscle, in spite of deliberate attempts to prevent this (Grimm, 1971; Holder et al., 1982, 1984; Stephenson, 1979), and initial, inappropriate connections may be displaced by appropriate ones (Dennis and Yip, 1978; cf. Wigston, 1980).

The mechanisms underlying the return of normal movements in teleosts are less well known. According to Sperry and Arora (1965) and Mark (1965), individual muscles are reinnervated exclusively by their original axons; but later electrophysiological evidence showed that muscles are also reinnervated by inappropriate axons (Mark and Marotte, 1972). Since the evidence for selective reinnervation is based solely on physiological and 


\begin{tabular}{|c|c|c|c|c|c|c|}
\hline $\begin{array}{l}\text { Animal } \\
\text { no. }\end{array}$ & ON & SRN & MRN & ION & IRN & PPA \\
\hline 2 & 447 & - & - & - & - & - \\
\hline 3 & 419 & - & - & - & - & - \\
\hline 18 & 431 & - & 73 & 101 & 90 & - \\
\hline 19 & 437 & - & 61 & 105 & - & - \\
\hline 111 & - & 114 & 74 & 88 & 108 & - \\
\hline 112 & - & 109 & 60 & 106 & - & - \\
\hline Mean & 434 & 112 & 67 & 100 & 99 & 56 \\
\hline
\end{tabular}

Since the myelinated axons in these nerves are almost exclusively motor (Scherer and Easter, 1984), these counts are estimates of the number of motoneurons in the corresponding motor pools. ON, oculomotor nerve; SKN, superior rectus nerve; MRN, medial rectus nerve; ION, inferior oblique nerve; IRN, inferior rectus nerve. The mean number of preganglionic parasympathetic axons (PPA) in the oculomotor nerve trunk was estimated by the formula, PPA =ON $(\mathrm{SRN}+\mathrm{MRN}+\mathrm{ION}+\mathrm{IRN})$.

behavioral tests (see Discussion), it seemed worthwhile to reinvestigate this issue with anatomical techniques. The motor pools of these muscles were mapped with retrogradely transported HRP both in normal goldfish and in those whose oculomotor nerve had been previously transected, and the pathway by which axons regenerate to their muscles was examined by light and electron microscopy. My results demonstrate that axons regenerate within the Schwann tubes of the distal nerve-stump, that they reinnervate individual muscles nonselectively, and that this nonselective innervation persists for at least 1 year. Part of this work has previously appeared in an abstract (Scherer, 1983).

\section{Materlals and Methods}

\section{Lesioning the oculomotor and trochlear nerves}

Commercially obtained, common goldfish (Carassius auratus) between 6 and $9 \mathrm{~cm}$ standard length were anesthetized by immersion in $0.1 \%$ aqucous tricaine methanc sulfonatc. The oculomotor and trochlcar nerves (Fig. 1) were exposed by removing a piece of the dorsal cranium, and the oculomotor nerve was transected with a hook of fine tungsten wire. In a few cases, both nerves were deliberately transected. The completeness of the lesion was assured by finding a gap of a millimeter or more between the proximal and distal nerve-stumps; no attempt was made to reappose them. The portion of cranium was replaced and sealed with a piece of Parafilm and cyanoacrylate adhesive. In other animals, the oculomotor nerve was similarly exposed but not lesioned (sham transection), or the trochlear nerve, but not the oculomotor, was transected.

\section{HRP labeling}

The motoneurons of extraocular muscles were labeled by either injecting individual muscles with HRP or applying HRP to the cut end of a proximal nerve-stump in anesthetized fish.

Individual muscles were injected with a concentrated aqueous solution of HRP (30-50\%) through glass micropipettes with tip diameters of about $20 \mu \mathrm{m}$. Usually the muscle was stained brown with the HRP solution; if it was not, and the HRP was found outside the muscle, then the animal was discarded. Properly stained muscles were immediately rinsed with saline, to remove any HRP that might have escaped, and then bathed in mineral oil, in order to inhibit any subsequent leakage of HRP. The wounds were covered with petroleum jelly, the animals were wrapped in wet paper towels, revived $30 \mathrm{~min}$ later, and returned to aquaria maintained between 18 and $25^{\circ} \mathrm{C}$.

The trochlear and inferior oblique nerves were labeled individually after removing the left eye (leaving the extraocular muscles intact) and placing their proximal stump in a piece of fine polyethylene tubing containing HRP or HRP plus $0.01 \%$ phospholipase $\mathrm{A}_{2}$ (Bixby et al., 1980). The orbit was packed with petroleum jelly and sealed with a piece of Parafilm and cyanoacrylate adhesive; the animal was wrapped in wet paper towels, then revived as above.

To label all of the motoneurons of the oculomotor nerve, animals

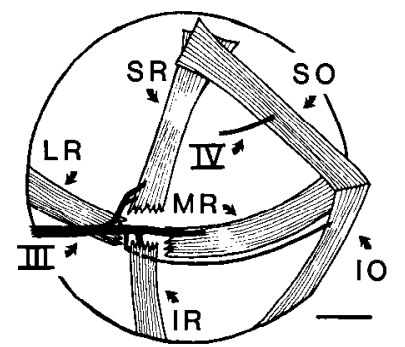

Figure 1. A sketch of the left eye of a goldfish, as seen from a dorsomedial view, simplified to show the oculomotor nerve (III), its four muscular branches, a portion of the trochlear nerve $(I V)$, and the extraocular muscles. The arrow pointing to the oculomotor nerve indicates where it was lesioned. $L R$, Lateral rectus; $S R$, superior rectus; $S O$, superior oblique; $M R$, medial rectus; $I O$, inferior oblique; $I R$, inferior rectus. Calibration, $1 \mathrm{~mm}$.

were perfused with ice-cold saline, and the proximal stump of the left nerve was placed in a piece of polyethylene tubing containing HRP. (This approach was adopted because animals invariably died soon after exposing the whole nerve-trunk to HRP.) The exposed area was flooded with mineral oil and packed with petroleum jelly. The animals were wrapped in wet paper towels and refrigerated at $4^{\circ} \mathrm{C}$ for $9-16 \mathrm{hr}$.

The brains of these refrigerated animals were fixed by immersion in $5 \%$ glutaraldehyde (in $0.08 \mathrm{M}$ phosphate buffer); the other animals were reanesthetized and perfused with $5 \%$ glutaraldehyde after $4-5 \mathrm{~d}$. The brains were removed, embedded in gelatin, and sectioned transversely at $50 \mu \mathrm{m}$. Serial sections were mounted on subbed glass slides, reacted with Hanker-Yates chromogen (Hanker et al., 1977), counterstained in methyl green, dehydrated, cleared, and coverslipped.

With many animals, after removing the brains, the oculomotor nerve and its branches were also removed. Some of these nerves were embedded in gelatin, serially sectioned, and processed like the brains. Others were left intact and reacted in $\mathrm{CoCl}_{2}$-diaminobenzidine (Adams, 1977), dehydrated, cleared, and coverslipped. Finally, some nerves were postfixed in $2 \% \mathrm{OsO}_{4}$ and processed for light and electron microscopy, as previously described (Scherer and Easter, 1984).

\section{Quantitative analysis}

Labelled motoneurons were plotted with the aid of a camera lucida, using a $20 \times$ objective, and the position of each labeled cell was confirmed under oil-immersion objectives $(50$ or $100 \times)$. To estimate the number of labeled cells, only oval envelopes of granular reaction product that were at least $5 \mu \mathrm{m}$ in depth were counted. The largest number of labeled cells in normal animals was seen after labeling the nerves to the inferior or superior obliques ( 84 and 60 , respectively). The number after labeling the muscles was generally lower, typically between 30 and 50 . Since the number of myelinated axons in each muscular nerve (Table 1) probably corresponds to the number of motoneurons in its motor pool, these counts underestimated the actual number of motoneurons by $20 \%$ or more.

Myelinated axons were counted from semithin sections, as previously described (Scherer and Easter, 1984).

\section{Results}

\section{Organization of the oculomotor system in normal goldfish}

Motor pools. Each side of the oculomotor nucleus in goldfish forms a crescent, which has been divided into a dorsolateral and a ventromedial nucleus (Hadidian and Dunn, 1938). To demonstrate the motor pools of the left oculomotor nerve, its proximal stump was labeled with HRP in three normal animals. In each case, labeled cells (examples of which are shown in Fig. 2) were found on both sides of the midline in the caudal half of the midbrain tegmentum. Labeled cells were seen throughout the ipsilateral crescent, whereas those on the contralateral (right) side were found only in the ventromedial nucleus (Fig. $3 A$ ).

Individual muscles of the left eye or their muscular nerves were labeled with HRP to demonstrate their motor pools (the number of animals is given in parentheses). The motor pool of 

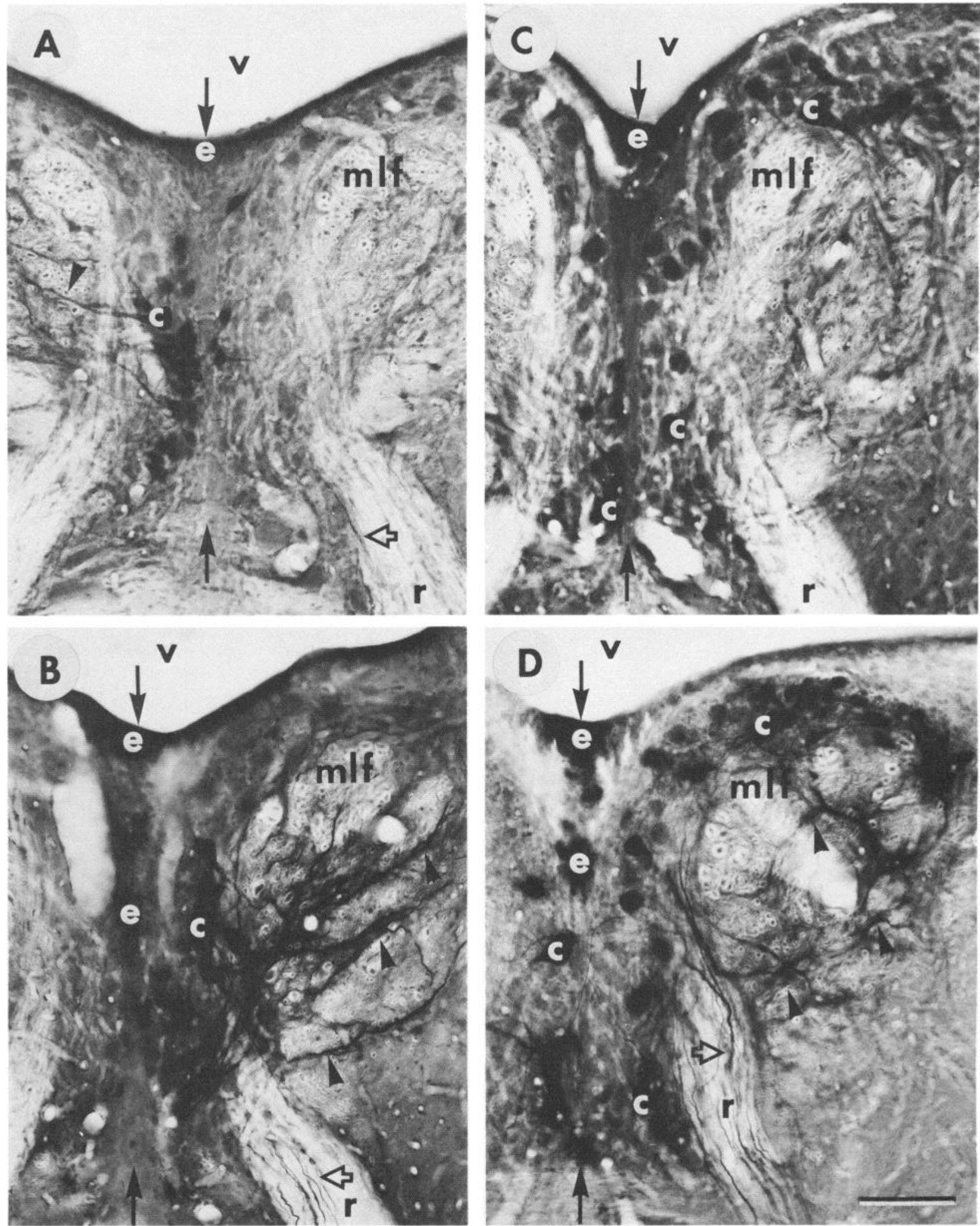

Figure 2. Photomicrographs of transverse sections through the oculomotor nucleus. The midline is indicated by solid arrows and the left side of each micrograph corresponds to the right side of the brains. Labeled cells $(c)$ appear darker than unlabeled ones; their positions are described in the text. Labeled dendrites (arrowheads), identified by their tapering branches, can be seen in $A, B$, and $D$ extending into the medial longitudinal fasciculus $(\mathrm{ml} / \mathrm{f})$. Labeled axons (open arrows), which are unbranched and do not taper, can be seen in $A, B$, and $D$ in the root of the oculomotor nerve $(r)$. Note the labeled ependymal cells $(e)$, especially in $B$ and $D$. $c$, Cerebellum; $v$, ventricle. $A$, Normal animal, superior rectus muscle label. $B$, Normal animal, inferior oblique nerve label. $C$, Superior rectus muscle label $31 \mathrm{~d}$ after transecting the oculomotor nerve (compare with $A$ ). $D$, Inferior oblique nerve label $182 \mathrm{~d}$ after transecting the oculomotor nerve (compare with $B$ ). Calibration, $100 \mu \mathrm{m}$. 
the superior rectus $(N=3)$ was mostly confined to the contralateral (right) ventromedial nucleus (Figs. $2 A$ and $3 B$ ). The motor pool of the inferior oblique $(N=11)$ was confined to the ipsilateral ventromedial nucleus (Figs. $2 B$ and $3 C$ ). The motor pool of the inferior rectus $(N=3)$ was confined to the ipsilateral dorsolateral nucleus (Fig. $3 D$ ). The motor pool of the medial rectus $(N=7)$ was found in the ipsilateral ventromedial and dorsolateral nuclei (Fig. $3 E$ ). Finally, the motor pool of the superior oblique $(N=7)$, the trochlear nucleus, was confined to the contralateral dorsolateral nucleus, just caudal to the oculomotor nucleus (Fig. 3F).

As summarized in Figure 3, the motoneurons of the superior rectus, inferior oblique, and inferior rectus occupied similar rostrocaudal positions, while those of the medial rectus extended caudad another $100 \mu \mathrm{m}$. In the transverse plane, the motor pools of the superior rectus, inferior oblique, and inferior rectus occupied discrete, nonoverlapping positions, while that of the medial rectus overlapped the latter two.

Microscopic anatomy. The light- and electron-microscopic features of the oculomotor nerve were examined. The nervetrunk and its branches were composed chiefly of myelinated axons. The myelin sheaths were formed by Schwann cells, which were surrounded by a basal lamina and collagen fibers (see also Scherer and Easter, 1984). The number of myelinated axons in the nerve-trunk and muscular branches was counted to estimate the number of motoneurons in each motor pool, including the preganglionic motoneurons of the ciliary ganglion cells (Table 1).

Whether the axons of the oculomotor nerve-trunk were organized into muscle-specific fascicles was also of interest, as this might be expected to influence the selectivity of axonal regeneration. This issue was investigated by labeling the inferior oblique nerve, and examining whole-mounted nerves reacted for $\operatorname{HRP}(N=16 ; 13$ normal animals and three sham operations). A camera lucida tracing of one of these whole-mounts is shown in Figure $4 A$. In this example, as in all others, the labeled axons could be traced from the inferior oblique nerve into the nerve-trunk, where they appeared to be dispersed among the unlabeled axons. No labeled axons were found in the other muscular branches. These impressions were confirmed and extended by examining the positions of labcled axons in transverse sections of six normal nerves that had been serially sectioned and reacted for HRP. One is shown in Figure 5.

\section{Organization of the oculomotor system in lesioned goldfish}

Motor pools. The axons that regenerated to the superior rectus muscle and the inferior oblique nerve were labeled in animals whose oculomotor nerve had been transected. If regenerating axons selectively reinnervated these muscles, then the distribution of labeled cells should have been identical to that in normal animals. If axonal regeneration was nonselective, on the other hand, then the labeled cells should have been distributed throughout the motor pools of the left oculomotor nerve.

The left superior rectus muscle was labeled between 16 and $271 \mathrm{~d}$ after transecting the oculomotor nerve $(N=27)$. Although the number of labeled cells varied widely between animals $(0-$ 114; note the higher than normal number of labeled cells), the pattern was always similar to the case shown in Figures $2 C$ and $3 G$. There were labeled cells in the contralateral, ventromedial nucleus, as in normal animals. However, labeled cells were more numerous on the ipsilateral side, both in the ventromedial nucleus, where they seldom appeared in normal animals, and in the dorsolateral nucleus, where they were never seen normally. Hence, it is clear that, after regeneration of the oculomotor nerve, the superior rectus muscle was reinnervated by inappropriate motoneurons of the oculomotor nucleus. In other words, axonal regeneration was nonselective.
Further evidence of nonselective reinnervation was obtained by labeling the left inferior oblique nerve between 17 and 586 $\mathrm{d}$ after transecting the oculomotor nerve $(N=35)$. Again, although the number of labeled cells varied ( $0-181$; note again the higher than normal number), the pattern was always similar to the case shown in Figures $2 D$ and $3 H$. The labeled cells were found throughout the motor pool of the left oculomotor nerve, on both sides of the midline; they were not confined to the portion that corresponded to the inferior oblique motor pool in normal animals.

Thus, there was a similar pattern of labeled cells in the oculomotor nucleus of lesioned animals when either the superior rectus muscle or the inferior oblique nerve was labeled. These results demonstrate that the superior rectus and inferior oblique muscles, and presumably the medial rectus and inferior rectus muscles, were nonselectively reinnervated after transecting the oculomotor nerve.

To evaluate the possibility that inappropriate axons were selectively lost with time, as in insects (Denburg, 1982; Whitington, 1979), I compared the number of labeled cells both ipsilateral and contralateral to the site of HRP application. In unlesioned animals, $89-98 \%$ (mean $=93 \%$ ) of the superior rectus motoneurons were contralateral, in contrast to $0-5 \%$ (mean $=$ $1 \%$ ) of the inferior oblique motoneurons (Fig. 6). In lesioned animals, on the other hand, this striking difference between the laterality of the motoneurons innervating these two muscles disappeared, as both were reinnervated by a similar percentage of contralateral cells; moreover, this percentage did not change with time (Fig. 6). Hence, nonselective reinnervation persisted for at least 1 year and perhaps indefinitely.

It was of interest to determine whether the percentage of contralateral cells in the motor pools of the reinnervated muscles was close to that for the oculomotor nerve itself. The latter figure was determined by counting the number of labeled, contralateral cells after applying HRP to the nerve-trunk in two normal animals. The percentage of contralateral cells was similar in both animals, and the mean (27\%) is shown by the dotted line in Figure 6 . The similarity of this figure $(27 \%)$ to those found for reinnervated muscles (Fig. 6) emphasizes the random nature of axonal regeneration in the oculomotor nerve.

Nonselective reinnervation of the trochlear nerve. Since axonal regeneration in the oculomotor nerve was nonselective, it was of interest to determine whether regenerating oculomotor axons could be misdirected into another, foreign nerve, as suggested by Mark (1974). The left trochlear nerve of one animal was labeled intraorbitally, distal to the site where both the left trochlear and the left oculomotor nerves had been transected $29 \mathrm{~d}$ prior to labeling. The labeled cells are shown in Figure $3 I$. They lay in both the oculomotor and trochlear nuclei, which demonstrates that oculomotor axons will innervate the trochlear nerve, confirming Mark (1974). Furthermore, the distribution of labeled cells throughout the oculomotor nucleus, and the fact that 33 of $103(32 \%)$ were contralateral, indicates that the trochlear nerve was reinnervated nonselectively, and perhaps randomly (see above), by the oculomotor axons.

Gross and microscopic anatomy of axonal regeneration. To determine the pathway by which regenerating axons reached the extraocular muscles, the left oculomotor nerve and its branches were carefully dissected in most lesioned animals. In almost every case, the nerve and its branches could be identified, and in no case was a muscle found to be innervated by either an extra or an abnormally placed nerve.

The axonal pathways within the nerves were examined in whole-mounted preparations of regenerated oculomotor nerves after labeling the inferior oblique nerve with HRP. Unlike normal and sham-transected nerves, in which labeled axons were found only in the inferior oblique nerve (see above), regenerated 


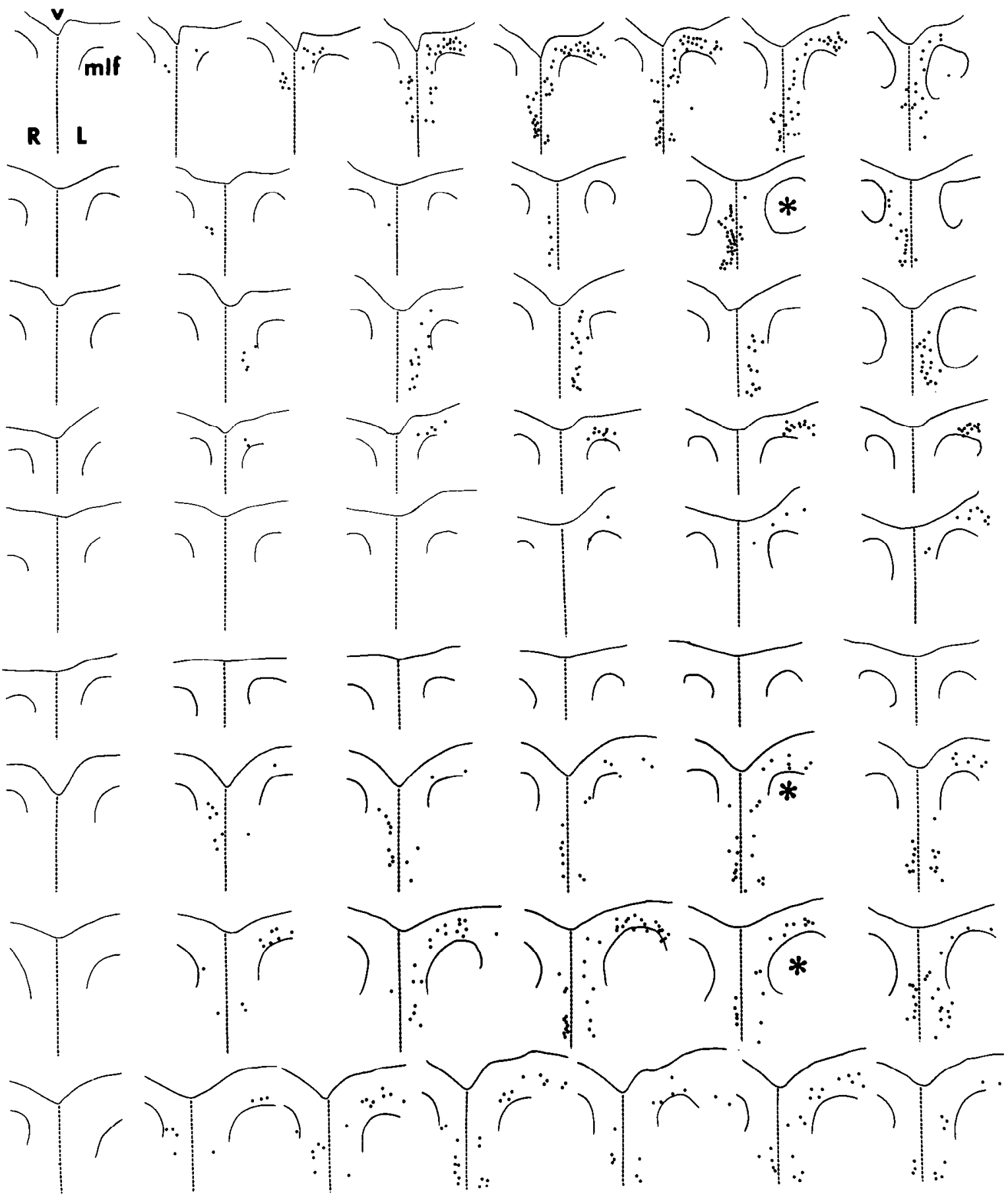

Figure 3. Camera lucida reconstructions of the oculomotor and trochlear nuclei from serial, transverse sections of the caudal midbrain. Each horizontal row of tracings continues across both parts of the figure and is derived from a single animal. Tracings from similar rostrocaudal levels of individual animals have also been aligned vertically to have a similar rostral-caudal level; rostral is to the left and caudal is to the right. In each tracing, the medial longitudinal fasciculus $(\mathrm{ml} / \mathrm{f})$ and the boundary between ventricle $(v)$ and tegmentum are indicated by solid lines; the midline by the dotted lines, and the positions of labeled cells by dots. The left $(L)$ and right $(R)$ sides of the brain are indicated, and sections marked by asterisks

nerves had labeled axons in all of the muscular branches (Fig. $4 B$ ). Presumably the HRP was transported both retrogradely to and beyond the point where axons branched, and orthogradely in the branch(es). This is clear evidence that some axons in the inferior oblique nerve had at least one branch (and possibly more) that entered another nerve, and is the first anatomical demonstration to my knowledge of misdirected axonal branches in a regenerated nerve.

Regenerated inferior oblique nerves were examined by light and electron microscopy for comparison with the degenerative and regenerative changes described in detail in the trochlear nerve of goldfish (Scherer and Easter, 1984). They were very similar. By $8 \mathrm{~d}$ postlesion, almost all the axons and their myelin sheaths were degenerating, but the Schwann cells and their basal laminae (the Schwann tubes) remained intact. Regenerating axons were found at $17 \mathrm{~d}$ and thereafter, and exclusively within the Schwann tubes. The axons were mostly nonmyelinated, 0.2$2 \mu \mathrm{m}$ in diameter, and in fascicles of 2-30 axons per Schwann 


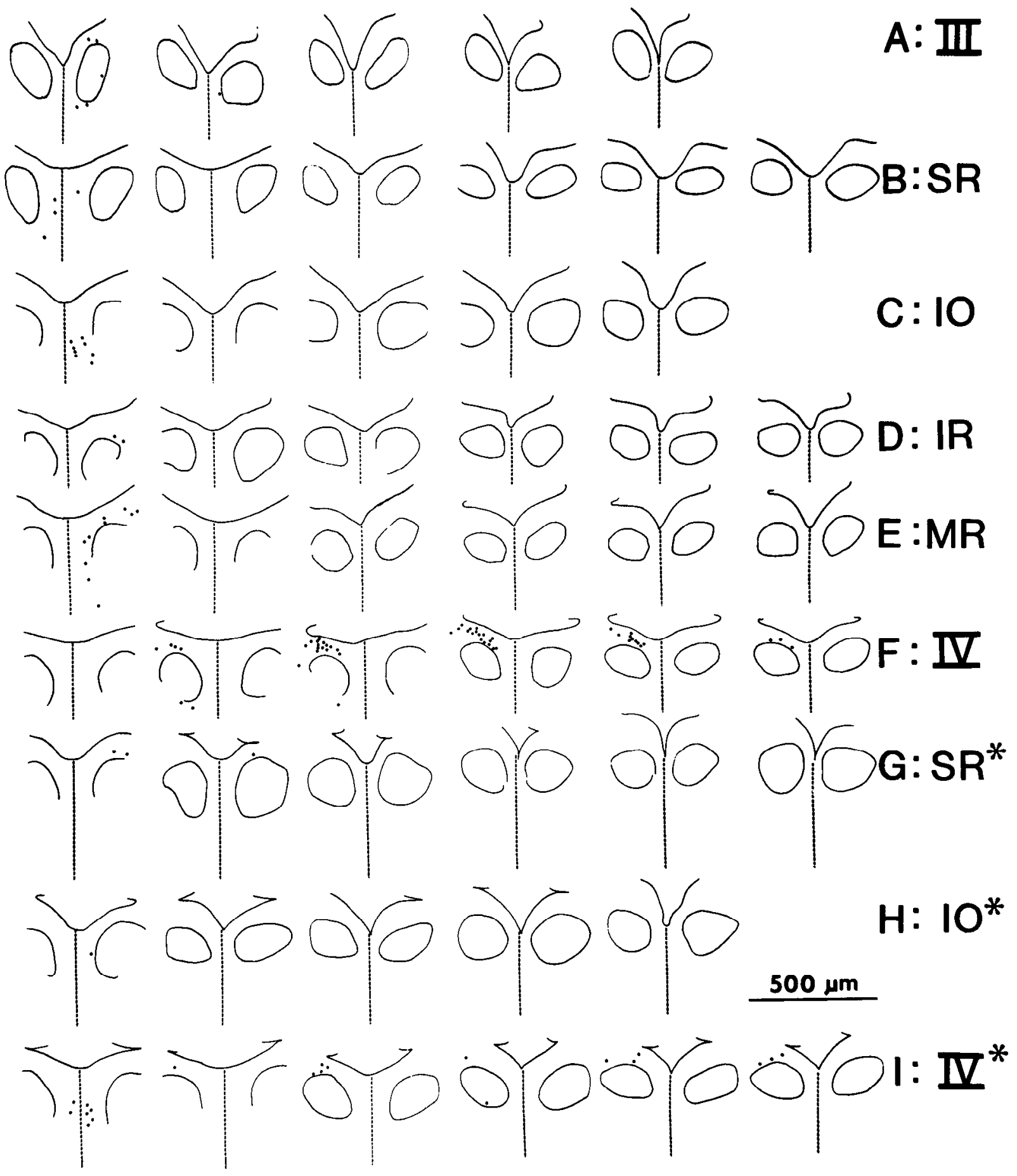

are shown photographically in Figure 2. $A-D$, Normal animals. $A, I I I$ : Oculomotor nerve label. $B, S R$ : Superior rectus muscle label. $C, I O$ : Inferior oblique nerve label. $D, I R$ : Inferior rectus muscle label. $E, M R$ : Medial rectus muscle label. $F, I V:$ Trochlear nerve label. $G$, $S R^{*}:$ Superior rectus muscle label $31 \mathrm{~d}$ after transecting the oculomotor nerve (compare to $B$ ). $H, I O^{*}$ : Inferior oblique nerve label $182 \mathrm{~d}$ after transecting the oculomotor nerve (compare to $C$ ). $I, I V^{*}$ : Trochlear nerve label $29 \mathrm{~d}$ after transecting the oculomotor and trochlear nerves (compare to $F$ ).

tube. Remyelinated axons were seen at $17 \mathrm{~d}$, and by $271 \mathrm{~d}$ postlesion they were about four times more numerous than in normal nerves (Fig. 7). The gradual increase in the number of myelinated axons probably resulted from remyelination of existing, nonmyelinated axons rather than from late sprouting (see Scherer and Easter, 1984). These quantitative data confirm that regenerating axons formed multiple, long-lived branches, and account for the higher than normal number of labeled cells observed in the oculomotor nucleus after regeneration of the nerve (see above).
Alternative explanations. The most obvious alternative to the conclusion that regenerating oculomotor axons reinnervated the extraocular muscles nonselectively is the possibility that axonal regeneration was selective, but that regenerated axons in the other muscles were labeled by the intraorbital leakage of HRP (see Levine, 1983). This is unlikely, since the transection of the nerve did not directly involve the orbital contents, and only in 5 of 31 normal animals did the intraorbital application of HRP label any cells (and they were always few) that were in motor pools outside of the expected one. To evaluate the importance 
Figure 4. Camera lucida tracings of whole-mounted oculomotor nerves whose inferior oblique branch has been labeled with HRP. The outline of each nerve and its muscular branches, as well as labcled axons, are shown. $A$, A normal oculomotor nerve. Selected, labeled axons can be traced from the inferior oblique serve $(I O N)$ to the oculomotor nerve trunk, where they appear to be dispersed among unlabeled axons. There are no labeled axons in the superior rectus nerve $(S R N)$, medial rectus nerve $(M R N)$, or inferior rectus nerve (IRN). $B$, An oculomotor nerve that was transected intracranially $182 \mathrm{~d}$ previously. Selected, labeled axons are traced as far as possible; they appear to be disarrayed in the proximal portion of the nerve trunk (to the left of the arrowheads), and are found in all of the muscular branches. Calibration, $500 \mu \mathrm{m}$.

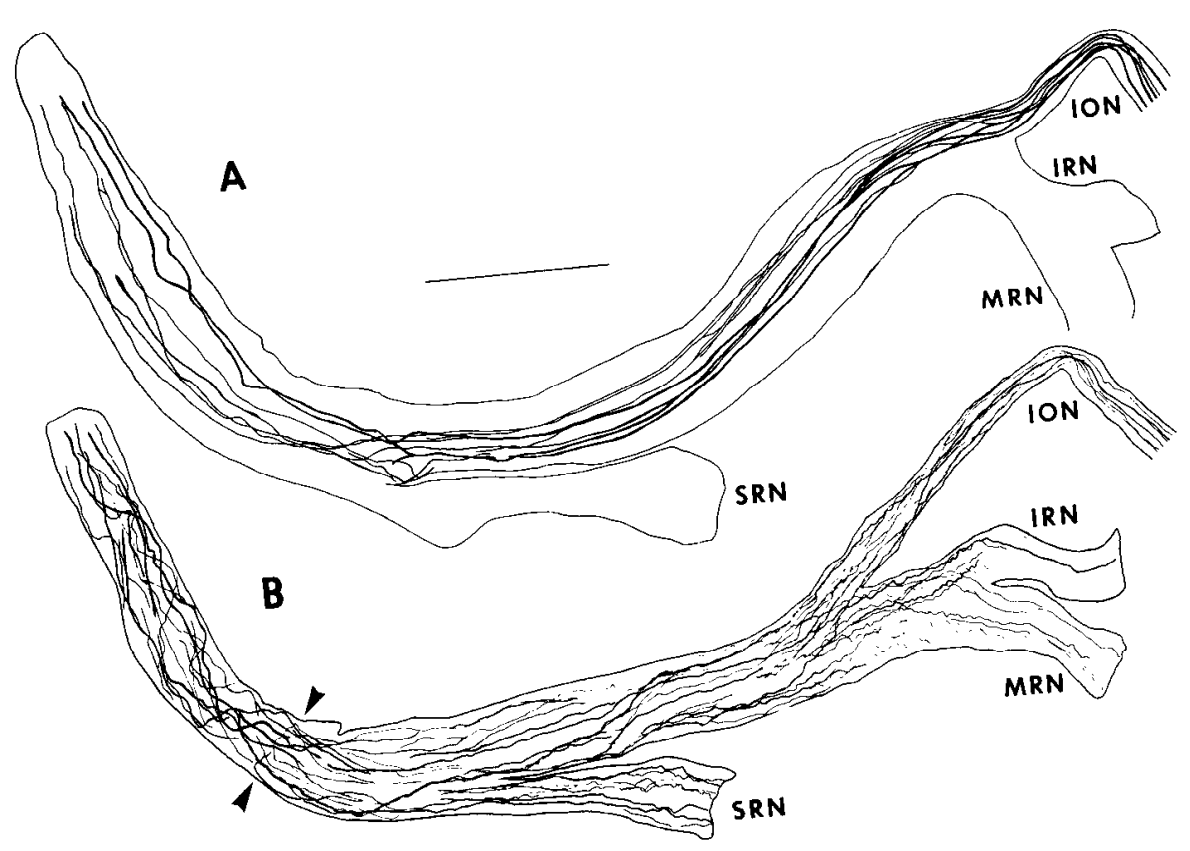

of intraorbital leakage, I injected the usual amount of HRP around, but not within, the left superior rectus muscle of two animals whose left oculomotor nerve had been transected $28 \mathrm{~d}$ before. The muscles were rinsed with saline and mineral oil in the usual manner, and the animals were processed identically to the other animals. No labeled cells were found; hence, the sloppy application of HRP does not account for the nonselective pattern of labeling.

Another alternative explanation is that reinnervated muscles, unlike normal muscles, slowly released HRP into the orbit, where it was picked up by axons in other muscles. This explanation is unlikely, first, because such lesion-induced permeability would have to have persisted for more than a year (Fig. 6 ), and, second, because it does not explain how labeling the inferior oblique nerve could have led to a nonselective pattern of labeling.

To show that the inappropriate, labeled cells were not a nonspecific result of surgery, either the inferior oblique nerve $(N=$ $4)$ or the superior rectus muscle $(N=2)$ was labeled in shamtransected animals. In addition, the superior rectus muscle was labeled in two animals whose trochlcar ncrve had been transected ( $31 \mathrm{~d}$ before), and the trochlear nerve was labeled in another animal whose oculomotor nerve had been transected ( $28 \mathrm{~d}$ before). In every case, the labeled cells were located only in the appropriate motor pool. This shows that nonspecific effects of surgery, including the degeneration of another nerve, did not cause the labeling of inappropriate cells.

Whether axotomy alone caused motoneurons to acquire endogenous peroxidase activity was also considered. Two animals whose left oculomotor nerve had been previously transected (17 or $107 \mathrm{~d}$ before) were perfused, and their brains were sectioned and reacted for HRP. No labeled cells were found, ruling out this possibility.

\section{Discussion}

\section{Recapitulation}

I have confirmed that axons in the oculomotor nerve regenerated exclusively within the Schwann tubes of the distal nerve-stump (Scherer and Easter, 1984). Two observations showed that re- generating axons often formed multiple branches-the presence of labeled axons in the other nerve-branches (Fig. $4 B$ ), and the increased number of myelinated axons in the inferior oblique nerve (Fig. 7). The nonselectivity of axonal regeneration was inferred from the observations that axonal branches reinnervated more than one muscular nerve (at lcast onc of which must have been inappropriate), and that both the superior rectus muscle and inferior oblique nerve were reinnervated by inappropriate motoneurons. Moreover, these inappropriate motoneurons and axonal branches persisted without any detectable change for more than a ycar.

\section{Nonselectivity of axonal regeneration}

To show that axonal regeneration is nonselective, I exploited the discreteness of the inferior oblique and superior rectus motor pools, and especially the unique, contralateral position of the latter. The positions of the motor pools in my work agree in general with those in previous work in teleosts (Graf and Baker, 1983; Leonard and Willis, 1979; Luiten and Dijkstra-de Vleiger, 1978; McGurk and Graf, 1984), with the exception of the early work of Hadidian and Dunn (1938), who illustrate extensive overlap between all of the motor pools in the oculomotor nucleus of goldfish.

My anatomical observations are inconsistent with the claim of Sperry and Arora (1965) that reinnervation of the extraocular muscles is selective. Their conclusion was based on three observations. First, eye movements were restored to normal after nerve-transection. Second, eye movements were permanently abnormal after various pairs of extraocular muscles were crossinnervated, which contradicted the idea that axons were respecified (Weiss, 1936), the prevailing view at that time. Third, axon reflexes between the muscular branches could not be elicited in regenerated nerves, which implied that if regenerating axons branched, then all of the branches must have reinnervated the same muscular nerve, which was evidence for selective reinnervation.

The later studies of Mark and his co-workers (Mark and Marotte, 1972; Mark et al., 1972; Marotte and Mark, 1970a, b) led to a different interpretation. In one series of experiments, they transected both the oculomotor and trochlear nerves intracra- 

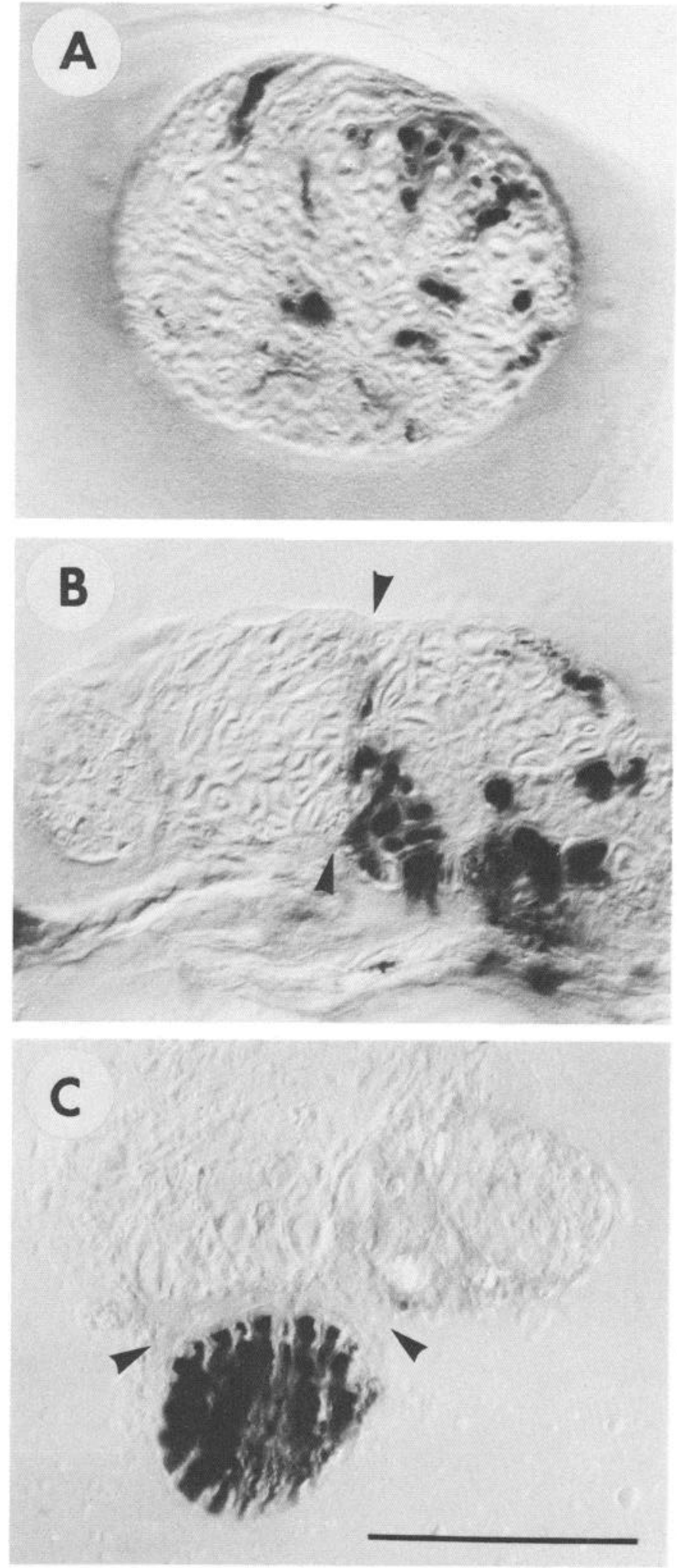

Figure 5. Transverse sections of a normal oculomotor nerve whose inferior oblique branch has been labeled with HRP. The sections were viewed with Nomarski interference contrast as they were not counterstained. $A$, Proximal portion of the nerve-trunk. Labeled axons are interspersed among unlabeled ones and are not stratified within the nerve. $B$, About $700 \mu \mathrm{m}$ distal to $A$. Labeled axons are not found in the superior rectus nerve (to the left of the arrowheads), but are mixed with unlabeled ones in the rest of the nerve. $C$, About $2000 \mu \mathrm{m}$ distal to $A$. Labeled axons are found only in the inferior oblique nerve (below arrowheads), and not in the medial rectus or inferior rectus nerves (above arrowheads). Calibration, $100 \mu \mathrm{m}$. nially to allow regenerating axons to enter inappropriate distal nerve-stumps. Like Sperry and Arora (1965), they observed normal eye movements after regeneration, but, in addition, they found an abnormal pattern of electrical activity in the trochlear and inferior oblique nerves, which indicated that inappropriate axons had indeed regenerated into these nerves (although they did not establish from which motor pools, as in this study). In a second series of experiments, they dually innervated the superior oblique muscle with its own nerve (the trochlear) as well as with the nerve to its main antagonist (the inferior oblique) and found again that eye movements were restored to normal without any evidence of degenerating synapses in the superior 


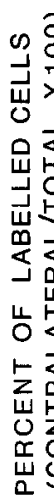

Figure 6. Percentage of labeled cells in the oculomotor nucleus that are contralateral to the labeled side, plottcd against the time after nervetransection. Each point represents a single, lesioned animal in which at least 10 cells were labeled, except at $0 \mathrm{~d}$, which shows the means of unlesioned animals (pooled data from normal and sham-operated animals $(N=7$, superior rectus; $N=11$, inferior oblique; SD too small to be illustrated). Triangles, Superior rectus muscle labels. Circles, Inferior oblique nerve labels. Note that the percentage of labeled, contralateral cells in lesioned animals does not change with time, but is markedly different from that in unlesioned animals. Dotted line, Percentage of contralateral, labeled cells in the oculomotor nucleus of normal animals (mean of two animals). For details, see text.

oblique muscle. They inferred from the two sets of experiments that inappropriate synapses had been repressed (maintained anatomically but inactivated electrically).

The elegant work of Scott (1977) contradicted this conclusion. She also dually innervated the superior oblique muscle, and showed that inappropriate (inferior oblique) axons could activate the superior oblique muscle even in the presence of appropriate innervation; this proved that inappropriate synapses were not repressed, as originally defined by Mark (1974; cf. 1980). In addition, she recorded a normal pattern of electrical activity from these inappropriate axons, proving that they were not respecified (Weiss, 1936).

Thus, my evidence that axonal regeneration is nonselective, together with Scott's (1977) demonstration that inappropriate axons form functional connections, is difficult to reconcile with the claim that normal eye movements are restorcd after ncrvetransection in teleosts (Sperry and Arora, 1965). Misdirected axons should cause permanently abnormal eye movements, as in mammals (Ford and Woodhall, 1938; Sperry, 1945; Walsh and Hoyt, 1969). It is problematic, in this regard, that Sperry and Arora (1965) did not report any objective measurements of eye movements beyond their visual impressions, as my own quantitative measurements reveal striking abnormalities (Scherer, unpublished observations). The only remaining evidence, then, for selective reinnervation of individual muscles is the abscnce of axon reflexes (Sperry and Arora, 1965)-a negative result that is inconsistent with my anatomical data. Although species differences might conceivably account for these discrepancies [Sperry and Arora, 1965, used oscars (Astronotus ocellatus), a cichlid, whereas Mark, Scott, and I used cyprinids], such a fundamental difference is unlikely.

\section{Another aspect of selective reinnervation}

To avoid confusion, the issue of whether individual axons regenerate to their appropriate muscle, as discussed throughout this paper, must be distinguished from that of whether they selectively reinnervate different types of muscle fibers. Individual twitch and tonic muscle fibers in the extraocular muscles of goldfish (Davey et al., 1975; Kilarski and Bigaj, 1969; Scott, 1977) may well have been selectively reinnervated as in anurans

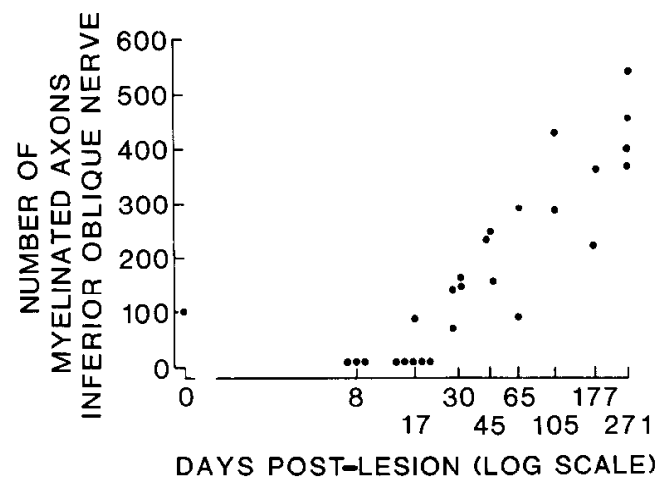

Figure 7. Number of myelinated axons in the inferior oblique nerve of lesioned and normal animals, plotted against time after oculomotor nerve transection. Each point represents a single, lesioned animal, except at $0 \mathrm{~d}$, which shows the mean of normal animals $(N=4$; SD too small to be illustrated).

(Elizalde et al., 1983; Hoh, 1971; Schmidt and Stefani, 1976), but this kind of selective reinnervation should not have complicated my analysis, as all of the extraocular muscles have fiber types of similar composition (Kilarski and Bigaj, 1969; McGurk and Graf, 1984). In anurans, the selective reinnervation of different fiber types occurs in spite of the fact that regenerating axons have been misdirected into inappropriate muscles (Farel, 1982; Westerfield and Powell, 1983), indicating that the two phenomena are independent.

\section{Conclusion}

This is the first anatomical study on the selectivity of axonal regeneration in the peripheral nervous system of teleosts, a group in which regenerating axons were believed to selectively reinnervate their original muscles (Sperry and Arora, 1965). I have found that axons regenerate within the Schwann tubes of the distal stump of the oculomotor nerve, that they reenter these Schwann tubes nonselectively, and that this nonselective innervation persists for at least 1 year. Thus, axonal regeneration in the peripheral nervous system of teleosts is not exceptional, but is like that described in mammals and anurans.

\section{References}

Adams, J. C. (1977) Technical considerations on the use of horseradish peroxidase. Neuroscience 2: 141-146.

Bixby, J. L., J. H. R. Maunsell, and D. C. Van Essen (1980) Effects of motor unit size on innervation patterns in neonatal mammals. Exp. Neurol. 70: 516-524.

Brushart, T. M., and M.-M. Mesulam (1980) Altcration in connections between muscle and anterior horn motoneurons after peripheral nerve repair. Science 208: 603-605.

Davey, D. F., R. F. Mark, L. R. Marotte, and U. Proske (1975) Structure and innervation of extraocular muscles of Carassius. J. Anat. 120: 131-147.

Denburg, J. L. (1982) Elimination of inappropriate axonal branches of regenerating cockroach motor neurons as detected by the retrograde transport of horseradish peroxidase conjugated wheat germ agglutinin. Brain Res. 248: 1-8.

Dennis, M. J., and J. W. Yip (1978) Formation and elimination of foreign synapses on adult salamander muscle. J. Physiol. (Lond.) 274: 299-310.

Elizalde, A., M. Huerta, and E. Stefani (1983) Selective reinnervation of twitch and tonic muscle fibres of the frog. J. Physiol. (Lond.) 340: 513-524.

Farel, P. B. (1982) Regeneration of developing spinal motoneurons. Soc. Neurosci. Abstr. 8: 436.

Ford, F. R., and B. Woodhall (1938) Phenomena due to misdirection of regenerating fibers of cranial, spinal and autonomic nerves. Arch. Surg. 36: 480-496.

Graf, W., and R. Baker (1983) Adaptive changes of the vestibulo- 
ocular reflex in flatfish are achieved by reorganization of central nervous pathways. Science 221: 777-779.

Grimm, L. M. (1971) An evaluation of myotypic respecification in axolotls. J. Exp. Zool. 178: 479-496.

Hadidian, Z., and M. S. Dunn (1938) Localization in the oculomotor nuclei of the goldfish. J. Comp. Neurol. 68: 191-203.

Hanker, J. S., P. E. Yates, C. B. Metz, and A. Rustioni (1977) A new specific, sensitive and non-carcinogenic reagent for the demonstration of horseradish peroxidase. Histochem. J. 9: 789-792.

Hoh, J. F. Y. (1971) Selective reinnervation of fast-twitch and slowgraded muscle fibers in the toad. Exp. Neurol. 30: 262-276.

Holder, N., J. Mills, and D. A. Tonge (1982) Selective reinnervation of skeletal muscle in the newt Triturus cristans. J. Physiol. (Lond.) 326: 371-384.

Holder, N., D. A. Tonge, and P. Jesani (1984) Directed regrowth of axons from a misrouted nerve to their correct muscles in the limb of the adult newt. Proc. R. Soc. Lond. [Biol.] 222: 477-489.

Horch, K. W. (1979) Guidance of regrowing sensory axons after cutaneous nerve lesions in the cat. J. Neurophysiol. 42: 1437-1449.

Kilarski, W., and J. Bigaj (1969) Organization and fine structure of extraocular muscles in Carassius and Rana. Z. Zellforsch. 94: 194204.

Langley, J. N. (1897) On the regeneration of preganglionic and postganglionic visceral nerve fibres. J. Physiol. (Lond.) 22: 215-230.

Leonard, R. B., and W. D. Willis (1979) The organization of the electromotor nucleus and extraocular motor nuclei in the stargazer (Astroscopus y-graecum). J. Comp. Neurol. 183: 397-414.

Levine, R. L. (1983) Widespread regeneration of central axons through the central nervous system of the goldfish. Dev. Brain Res. 9: 416419.

Luiten, P. G. M., and H. P. Dijkstra-de Vlieger (1978) Extraocular muscle representation in the brainstem of the carp. J. Comp. Neurol. 179: 903-912.

Mark, R. F. (1965) Fin movements after regeneration of neuromuscular connections: An investigation of myotypic respecification. Exp. Neurol. 12: 292-302.

Mark, R. F. (1974) Selective innervation of muscle. Br. Med. Bull. 30: $122-126$.

Mark, R. F. (1980) Synaptic repression at neuromuscular junctions. Physiol. Rev. 60: 355-395.

Mark, R. F., and L. R. Marotte (1972) The mechanism of reinnervation of fish eye muscles. III. Functional, electrophysiological, and anatomical analysis of recovery from section of the IIIrd and IVth nerves. Brain Res. 46: 131-148.

Mark, R. F., L. R. Marotte, and P. E. Mart (1972) The mechanism of reinnervation of fish eye muscles. IV. Identification of repressed synapses. Brain Res. 46: 149-157.

Marotte, L. R., and R. F. Mark (1970a) The mechanism of selective reinnervation of fish eye muscle. I. Evidence from muscle function during recovery. Brain Res. 19: 41-51.

Marotte, L. R., and R. F. Mark (1970b) The mechanism of selective reinnervation of fish eye muscle. II. Evidence from electron microscopy of nerve endings. Brain Res. 19: 53-62.
McGurk, J. F., and W. Graf (1984) The oculomotor system of the goldfish, Carassius auratus. Soc. Neurosci. Abstr. 10:986.

Mizuno, N., M. Uamura, K. Matsuda, Y. Takenchi, M. Kume, and R. Matsushima (1980) Non-selective distribution of hypoglossal nerve fibers after section and resuture. Neurosci. Lett. 19: 33-37.

Osborne, W. A., and B. Kilvington (1908a) Axon bifurcation in regenerated nerves. I. J. Physiol. (Lond.) 37: 1-11.

Osborne, W. A., and B. Kilvington (1908b) Axon bifurcation in regenerated nerves. II. J. Physiol. (Lond.) 38: 268-275.

Purves, D., and J. W. Lichtman (1984) Principles of Neural Development, Sinauer, Sunderland, MA.

Ramón y Cajal, S. (1928) Degeneration and Regeneration of the Nervous System, R. M. May, Trans., Oxford, Oxford, UK.

Scherer, S. S. (1983) Non-selectivity of axonal regeneration in the oculomotor nerve of goldfish. Soc. Neurosci. Abstr. 9: 47.

Scherer, S. S., and S. S. Easter, Jr. (1984) Degenerative and regenerative changes in the trochlear nerve of goldfish. J. Neurocytol. 13: $519-565$.

Schmidt, H., and E. Stefani (1976) Innervation of twitch and slow muscle fibres in the frog after crushing the motor nerves. J. Physiol. (Lond.) 258: 99-123.

Scott, S. A. (1977) Maintained function of foreign and appropriate junctions on reinnervated goldfish extraocular muscles. J. Physiol. (Lond.) 268: 87-109.

Sperry, R. W. (1945) The problem of central nervous system reorganization after nerve regeneration and muscle transposition. Q. Rev. Biol. 20: 311-369.

Sperry, R. W. (1947) Nature of functional recovery following regeneration of the oculomotor nerve in amphibians. Anat. Rec. 97: 293 316.

Sperry, R. W., and L. Arora (1965) Selectivity in the regeneration of the oculomotor nerve in the cichlid fish, Astronotus ocellatus. J. Embryol. Exp. Morph. 14: 307-317.

Stephenson, R. S. (1979) Axon reflexes in axolotl limbs: Evidence that branched motor axons reinnervate muscles selectively. Exp. Neurol. 64: 174-184.

Thomas, P. K. (1964) Changes in the endoneurial sheaths of peripheral myelinated nerve fibres during Wallerian degeneration. J. Anat. 98: 175-182.

Walsh, F. B., and W. F. Hoyt (1969) Clinical Neurophthalmology, pp. 256-261, Williams and Wilkins, Baltimore, MD.

Weiss, P. (1936) Selectivity controlling the central-peripheral relations of the nervous system. Biol. Rev. 11: 494-531.

Weiss, P., and A. Hoag (1946) Competitive reinnervation of rat muscle by their own and foreign nerves. J. Neurophysiol. 9: 413-418.

Westerfield, M., and S. L. Powell (1983) Selective reinnervation of limb muscles of regenerating frog motor axons. Dev. Brain Res. 10: 301-304.

Whitington, P. M. (1979) The specificity of innervation of regenerating motor neurons in the cockroach. J. Comp. Neurol. 186: 465-472.

Wigston, D. J. (1980) Suppression of sprouted synapses in axolotl muscle by transplanted foreign nerves. J. Physiol. (Lond.) 307: 355366. 